\title{
Prevalence and genotyping of Helicobacter pylori in endoscopic biopsy samples from a Chinese population
}

https://doi.org/10.1515/labmed-2018-0324

Received March 3, 2018; accepted May 3, 2018; previously published online June 2, 2018

\section{Abstract}

Background: Helicobacter pylori inhabit the gastric mucosa of humans and are associated with several gastrointestinal diseases which include gastric cancer, peptic ulcer, chronic gastritis and gastric mucosa-associated lymphoid tissue lymphoma. Helicobacter pylori exhibit a high degree of genetic variability and are associated with its epidemiological, pathological characteristics and dynamics of transmission. The objective of the study was to determine the prevalence and genetic heterogeneity of $H$. pylori isolated from endoscopic biopsy samples from a Chinese population.

Methods: Gastric biopsy samples from 86 patients (males, 55; females, 35) who presented to the endoscopic section for various gastrointestinal abnormalities were collected. The samples were subjected to a real-time polymerase chain reaction (PCR) and microbial culture for the isolation of $H$. pylori. Further, the isolates were subjected to randomly amplified polymorphic DNA (RAPD) and restriction fragment length polymorphism (RFLP) analysis.

Results: Of the 86 gastric biopsy samples, 61 (70.9\%) samples were positive for rapid urease test and 37 (43\%) samples (28 from male and nine from female) grew H. pylori. Among the biopsy samples subjected to realtime PCR, 39 (45.3\%) samples were found to be positive for $H$. pylori. The RAPD analysis yielded 15 different

\footnotetext{
*Correspondence: Lei Wang, Department of Oncology, Chifeng Hospital, Chifeng 024000, P.R. China, Phone/Fax: 0086-04768331476, E-Mail: LouisemCollinshy@yahoo.com

Hao Yu and Yingjia Mao: Medical Laboratory, Chifeng Hospital, Chifeng, P.R. China

Lijie Cong: Department of Digestive Internal Medicine, Chifeng Hospital, Chifeng, P.R. China

Zhiyong Wang: Endoscopy Room, Chifeng Hospital, Chifeng, P.R. China
}

Hua Zhang: Pathology Laboratory, Chifeng Hospital, Chifeng, P.R. China patterns (four to 17 different sized fragments per strain). The phylogenetic analysis of RAPD yielded 22 clusters at a similarity level ranging from $63 \%$ to $100 \%$. RFLP analysis yielded nine different patterns (two to six different sized fragments per strain). Two major restriction patterns were identified, of which 14 (37.8\%) strains forms the most common pattern (genotype I) followed by five (13.5\%, genotype II) strains with an intra-strain similarity of 100\%.

Conclusions: The overall prevalence of $H$. pylori was $45.3 \%$. Despite reports on the declining trend in the prevalence of $H$. pylori infections, our prevalence rate was still higher than those reported from other developed countries. However, further studies involving a large sample size and covering more regions of China is highly warranted.

Keywords: biopsy sample; Helicobacter pylori; randomly amplified polymorphic DNA (RAPD); restriction fragment length polymorphism (RFLP).

\section{Introduction}

Helicobacter pylori inhabit the gastric mucosa of humans and are associated with several gastrointestinal diseases which include chronic gastritis, peptic ulcer, gastric cancer and gastric mucosa-associated lymphoid tissue lymphoma [1, 2]. It has also been implicated in extragastrointestinal diseases such as cardiovascular diseases, diabetes mellitus and autoimmune diseases [3]. The prevalence of $H$. pylori varies based on age, ethnicity, geography and socio-economic status [1]. A systematic review and a meta-analysis which assessed the worldwide prevalence of $H$. pylori infection reported a large variation among different countries and found more than half of the world's population to be infected [4]. In many developed countries due to the improved socio-economic standards of living, the incidence of $H$. pylori tends to be low. However, it remained high, especially in developing countries which has a very low socio-economic status and poor sanitation practice $[5,6]$. In developed countries, 
the prevalence of $H$. pylori is significantly lower, accounting for up to $25 \%-50 \%$, compared to that in developing countries, accounting for $70 \%-90 \%$ of the population [7, 8]. In China, due to rapid urbanization, the prevalence of $H$. pylori is most likely decreasing [9]. However, the implications of $H$. pylori infection in the clinical health status of diseased patients and also healthy subjects, emphasize the importance to understand its prevalence at any given time point.

Helicobacter pylori exhibit a high degree of genetic variability and are associated with its epidemiological, pathological characteristics and dynamics of transmission [10]. Studies have reported that due to the diversity there is a difference in the pathogenicity of $H$. pylori and certain genotypes were detected in certain populations $[1,11]$. The recurrence of $H$. pylori infection after apparent eradication has been reported; however, it was unclear whether the recurrence of the ulcer was due to exogenous re-infection by another strain or due to previous infection [12]. Hence, it is highly important to accurately detect and differentiate $H$. pylori strains for better patient management and to quell the long-term consequences of continued asymptomatic diseases [13]. Conventional typing methods such as biotyping, hemagglutination, plasmid profiling, immunoblotting and cytotoxin activity assay were available. They exist with some inherent difficulties which limit their widespread use for the precise differentiation of $H$. pylori strains [13-15]. Molecular methods such as multilocus sequence typing, pulsedfield gel electrophoresis and ribotyping were reported to be highly discriminatory $[11,16]$. However, they are time-consuming, laborious, require technical expertise and are expensive. The polymerase chain reaction (PCR)based restriction fragment length polymorphism (RFLP) and randomly amplified polymorphic DNA (RAPD) analyses have been developed for $H$. pylori genotyping [17, 18]. The RAPD analysis which uses short oligonucleotide primers is a low stringent technique and requires DNA in nanogram quantities [11]. The RFLP analysis involves a restriction enzyme to fragment the specifically amplified region of the DNA to produce a genetic profile. The urease and its accessory proteins encoded UreA, UreB, UreC and UreD genes were used for the RFLP analysis of H. pylori [19]. Both RFLP and RAPD methods of genotyping are reported to be rapid, easy and highly discriminatory and can be used in clinical laboratory settings than other typing methods [11]. The aim of the present study is to determine the prevalence and genetic heterogeneity of $H$. pylori isolated from endoscopic biopsy samples from a Chinese population by real-time PCR, RFLP and RAPD techniques, respectively.

\section{Materials and methods}

\section{Patients}

A total of 86 consecutive gastric biopsy samples from 86 patients who were presented to the endoscopic section for various gastrointestinal abnormalities at the Chifeng Hospital, Chifeng, China between November 2016 and October 2017 were collected. The Chifeng Hospital situated at the urban city of Chifeng has two affiliated hospitals consisting of up to 1400 beds, covering a population from four surrounding provinces. Patients who received prior antibiotic therapy within 2 weeks and who had previous gastric surgery were excluded from the study. The hospital Ethical Committee approved the study and informed consent was obtained from all the patients. Samples were collected in a sterile container, sent immediately for microbiology analysis and the remaining samples were frozen at $-80{ }^{\circ} \mathrm{C}$ until used for real-time PCR.

\section{Isolation and Identification of $\boldsymbol{H}$. pylori}

The obtained samples were dissected under aseptic conditions into three parts for a rapid urease test, $H$. pylori culture and real-time PCR. A rapid urease test was performed using the modified rapid urease agar medium as described by Shahidi et al. [20]. Briefly, immediately after collection, biopsy samples were inoculated into urea agar and incubated at room temperature. The change in color of the medium from yellow to red at a maximum incubation period of $2 \mathrm{~h}$ indicates a positive reaction. Helicobacter pylori culture was done as described by Farshad et al. [21]. Briefly, biopsy samples were inoculated on the modified Columbia agar plates (Merck, Germany) supplemented with $10 \%$ lysed horse blood. The plates were then incubated in an anaerobic jar at $37{ }^{\circ} \mathrm{C}$ for 2-3 days under microaerobic conditions. After incubation, based on the colony morphology, gram staining, positive catalase, oxidase, and urease tests the organisms were identified as $H$. pylori. The isolates were stored in Columbia broth (Merck, Germany) supplemented with 20\% sterile glycerol at $-70{ }^{\circ} \mathrm{C}$ until used.

\section{DNA extraction}

DNA from the biopsy samples for real-time PCR was extracted using QIAamp DNA FFPE Tissue Kit (Qiagen, Hilden, Germany) as per manufacturer's protocol. DNA from $H$. pylori isolates for RAPD was extracted using the 
boiling lysis method, briefly, $200 \mu \mathrm{L}$ of $H$. pylori culture was incubated at $95{ }^{\circ} \mathrm{C}$ for $10 \mathrm{~min}$. Then samples were centrifuged at $14,000 \mathrm{~g}$ for $10 \mathrm{~min}$ and the supernatant containing DNA was collected. Both the DNA samples were stored at $-20{ }^{\circ} \mathrm{C}$ until DNA quantification and purity was determined using spectrophotometry (NanoDrop ND-1000, USA).

\section{Real-time PCR}

A real-time qualitative PCR (QuantStudio ${ }^{\mathrm{TM}} 7$ Flex RealTime PCR System, Applied Biosystems) to detect the presence of $H$. pylori in the biopsy samples was performed using the following $16 \mathrm{~S}$ rRNA primers $5^{\prime}$-GCGACCTGCTGGAACATTAC-3' and 5-CGTTAGCTGCATTACTGGAGA-3' [1] The PCR cycling conditions were as follows: 40 cycles of $95^{\circ} \mathrm{C}$ for $50 \mathrm{~s}, 60{ }^{\circ} \mathrm{C}$ for $50 \mathrm{~s}$ and $72{ }^{\circ} \mathrm{C}$ for $50 \mathrm{~s}$. Using an inbuilt intuitive software, a melt-curve analysis was performed to detect non-specific amplifications. The sample was considered positive when two of the three triplicate showed a positive result within the $<35$-cycle cut-off.

\section{RAPD}

The RAPD was done as described by Lin et al. [11] with a slight modification in the cycling condition. The $25 \mu \mathrm{L}$ reaction mixture contains $5 \mu \mathrm{L}$ of the template, $10 \mathrm{pmol}$ of primer PJ1118: 5'-TGTTCGTGCTGTTTCTG-3' and $12.5 \mu \mathrm{L}$ of $2 \mathrm{X}$ PCR master mix (Promega, USA). PCR cycling conditions were initial denaturation at $94^{\circ} \mathrm{C}$ for $5 \mathrm{~min}$, followed by 35 cycles of denaturation at $94^{\circ} \mathrm{C}$ for $1 \mathrm{~min}$, the annealing temperature of $45^{\circ} \mathrm{C}$ for $2 \mathrm{~min}$, extension at $72^{\circ} \mathrm{C}$ for $2 \mathrm{~min}$ and a final extension at $72^{\circ} \mathrm{C}$ for $10 \mathrm{~min}$. After PCR, the amplicons were resolved in $1.5 \%(\mathrm{w} / \mathrm{v})$ agarose gel and the pattern of amplicons were analyzed in comparison with a DNA marker.

\section{RFLP}

The H. pylori phosphoglucosamine mutase encoded UreC (glmM) gene, was amplified for RFLP analysis as described by Ozbey et al. [22]. The $50 \mu \mathrm{L}$ reaction mixture contains $5 \mu \mathrm{L}$ of the template, $10 \mathrm{pmol}$ of each primer (forward: 5'-AAG AAG TCA AAA ACG CCC CAA AAC-3' and reverse: 5'-CTT ATC CCC ATG CAC GAT ATT CCC-3') and $25 \mu \mathrm{L}$ of $2 \mathrm{X}$ PCR master mix (Promega, USA). PCR cycling conditions were initial denaturation of $94^{\circ} \mathrm{C}$ for $5 \mathrm{~min}, 45$ cycles of denaturation at $94^{\circ} \mathrm{C}$ for $45 \mathrm{~s}$, annealing temperature of 59 ${ }^{\circ} \mathrm{C}$ for $30 \mathrm{~s}$, extension at $72{ }^{\circ} \mathrm{C}$ for $90 \mathrm{~s}$ and a final extension at $72{ }^{\circ} \mathrm{C}$ for $10 \mathrm{~min}$. After PCR, $15 \mu \mathrm{L}$ of the amplicons were digested with $10 \mathrm{U}$ of HhaI (Promega, USA) restriction enzymes as per manufacturer's instructions for $4 \mathrm{~h}$ at $37^{\circ} \mathrm{C}$. The digested products were resolved in $2 \%(\mathrm{w} / \mathrm{v})$ agarose gel and the patterns of amplicons were analyzed in comparison with a DNA marker.

\section{Phylogenetic tree analysis}

A phylogenetic tree was constructed for RFLP and RAPD; fingerprints obtained with specific primers were analyzed separately as a single data set to obtain a single dendrogram. They were coded in binary form 1 or 0 , respectively. The NTSYSpc 2.11p software (Exeter Software, Setauket, USA) was used for clustering and phylogenetic tree construction.

\section{Statistical analysis}

Continuous variables were presented as mean and ranges; categorical variables as numbers and percentages. Chi-squared $\left(\chi^{2}\right)$ tests were performed to determine the statistical significance using Minitab statistical software (Minitab version 13.1; Minitab Inc, PA, USA). A p value of $<0.05$ was considered as statistically significant.

\section{Results}

Of the 86 patients, 51 (59.3\%) were male and 35 (40.7\%) were female. The mean age was $39.5 \pm 7.2$ years (range 19-59 years). A majority of the patients had gastric ulcer; $37(43.0 \%)$ followed by gastritis $26(30.2 \%)$ (Table 1$)$. Of the 86 gastric biopsy samples, $61(70.9 \%)$ samples were positive for rapid urease test and 37 (43\%) samples (28 from male and nine from female) grew $H$. pylori. All the samples which isolated $H$. pylori were found to be positive for rapid urease test. Among the biopsy samples subjected to realtime PCR, 39 (45.3\%) samples (29 from male and 10 from female) were found to be positive for $H$. pylori. Although more number of samples were positive for $H$. pylori by real-time PCR, they did not differ significantly $(\mathrm{p}>0.05)$. However, significantly higher numbers of gastric ulcer biopsy samples were positive for $H$. pylori when tested using real-time PCR $(\mathrm{p}=0.003)$ and using the culture method $(p=0.034)$ (Table 2).

The RAPD analysis yielded 15 different patterns with a minimum of four different size amplicons per strain to 
Table 1: Demographic detail of the patients.

\begin{tabular}{lr}
\hline Demographic details & $\mathbf{n}(\%)$ \\
\hline Male & $59(59.3)$ \\
Female & $35(40.7)$ \\
Age, years (mean \pm SD) & $39.5 \pm 7.2$ \\
Gastritis & $26(30.2)$ \\
Gastric ulcer & $37(43.0)$ \\
Duodenal ulcer & $18(20.9)$ \\
Gastric cancer & $5(5.8)$ \\
Smokers & $31(36.0)$ \\
Alcohol consumption & $57(66.3)$ \\
\hline
\end{tabular}

Table 2: Real-time PCR and biopsy culture results.

\begin{tabular}{lrr}
\hline Description (n) & $\begin{array}{r}\text { Real-time } \\
\text { PCR, } \mathbf{n}(\%)\end{array}$ & $\begin{array}{r}\text { H. pylori culture } \\
\text { positive, } \mathbf{n}(\%)\end{array}$ \\
\hline Male (59) & $29(49.2)$ & $24(40.7)$ \\
Female (35) & $10(28.6)$ & $13(37.1)$ \\
Gastritis (26) & $15(57.7)$ & $11(42.3)$ \\
Gastric ulcer (37) & $29(78.4)$ & $23(62.2)$ \\
Duodenal ulcer (18) & $9(50.0)$ & $3(16.7)$ \\
Gastric cancer (5) & $0(0)$ & $0(0)$ \\
Smokers (31) & $18(58.1)$ & $12(38.7)$ \\
Alcohol consumption (57) & $27(47.4)$ & $24(42.1)$ \\
\hline
\end{tabular}

a maximum of 17 different size amplicons per strain. The amplicons size ranged from $50 \mathrm{bp}$ to $>1500 \mathrm{bp}$ (Figure 1). The phylogenetic analysis of RAPD yielded 22 clusters at a similarity level ranging from $63 \%$ to $100 \%$. A total of ten (27\%) strains (strain numbers 2, 16, 19, 20, 21, 23, 25, 26, 29,37 ) showed $100 \%$ intra-strain similarity. Of these, eight were isolated from gastric ulcer patients and two were isolated from gastritis patients. A total of nine (24.3\%) strains

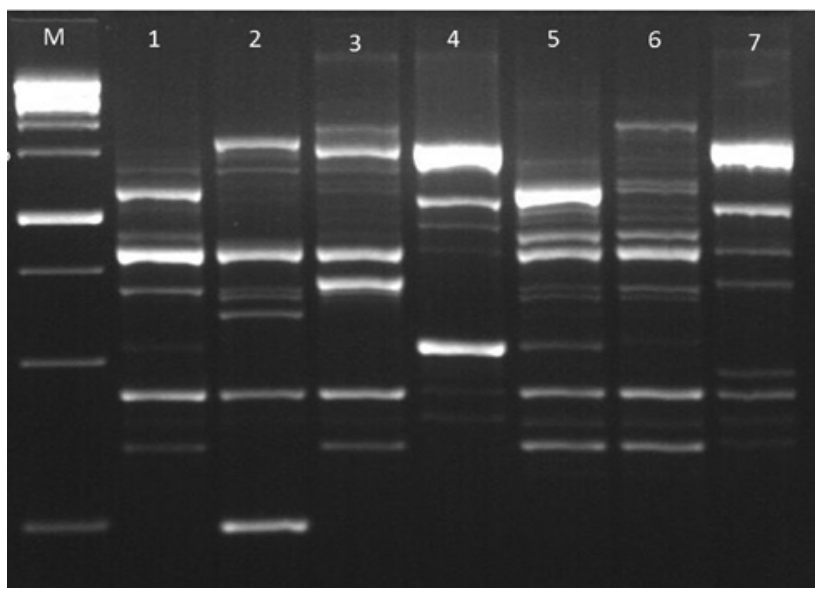

Figure 1: A representative gel picture showing the PCR-RAPD patterns, M: 100 bp DNA ladder, 1-7: Samples showing different DNA patterns. (strain numbers 3, 5, 6, 10, 13, 15, 30, 31, 35) showed an intra-strain similarity of $\geq 90 \%$. Of these, six were isolated from gastric ulcer patients; two were isolated from gastritis patients and one was isolated from duodenal ulcer patient. Overall, the RAPD analysis revealed high heterogeneity among our isolates (Figure 2).

All the 37 isolates were positive for UreC gene (1169 bp) using PCR. The amplicons were digested with HhaI restriction enzyme and yielded nine different patterns (designated as genotype I to IX) with a minimum of two fragments per strain to a maximum of six fragments per strain (Figure 3). Two major restriction patterns were identified, of which $14(37.8 \%)$ strains (strain numbers 10, 11, 16, 20, $21,23,25,26,28,29,31,33,35,37)$ forms the most common pattern (genotype I) followed by five (13.5\%, genotype II) strains (strain numbers 3, 6, 9, 15, 36) with an intra-strain similarity of $100 \%$, respectively. Of 14 strains which showed the most common pattern (genotype I), seven were isolated from gastric ulcer patients, five were isolated from gastritis patients and two were isolated from duodenal ulcer patients. All the five strains which showed the second most common pattern (genotype II) were isolated from gastric ulcer patients. Although $37.8 \%$ of our isolates were identified with genotype I, the RFLP analysis of the remaining strains revealed high heterogeneity (Figure 4).

\section{Discussion}

Recent studies suggest that the prevalence of $H$. pylori is declining in many countries especially in the developed countries [9, 23], while in the developing countries it remains high and varies from $70 \%$ to $90 \%$ [5-8]. In our study $45.3 \%$ of our biopsy samples were positive for $H$. pylori by realtime PCR, compared to the culture method (43\%). As these rates did not differ significantly and the fact that real-time PCR is highly sensitive, we considered the rate yielded by real-time PCR as our prevalence rate and discussed below. Helicobacter pylori are associated with various gastrointestinal diseases and continue to be a major health problem worldwide [1, 2, 4]. The overall prevalence of $H$. pylori in our study was reported to be $45.3 \%$. As there were limited studies on the prevalence of $H$. pylori isolated from gastric biopsy samples, we have compared our results with studies that reported its prevalence in the normal population as well as with different disease conditions. A recent study from urban China which determined the seroprevalence of $H$. pylori in a normal population, reported an overall prevalence of $31.9 \%$ and it varied from $46.8 \%$ to $80.4 \%$ in other parts of China [23-27]. In this study, the prevalence was 


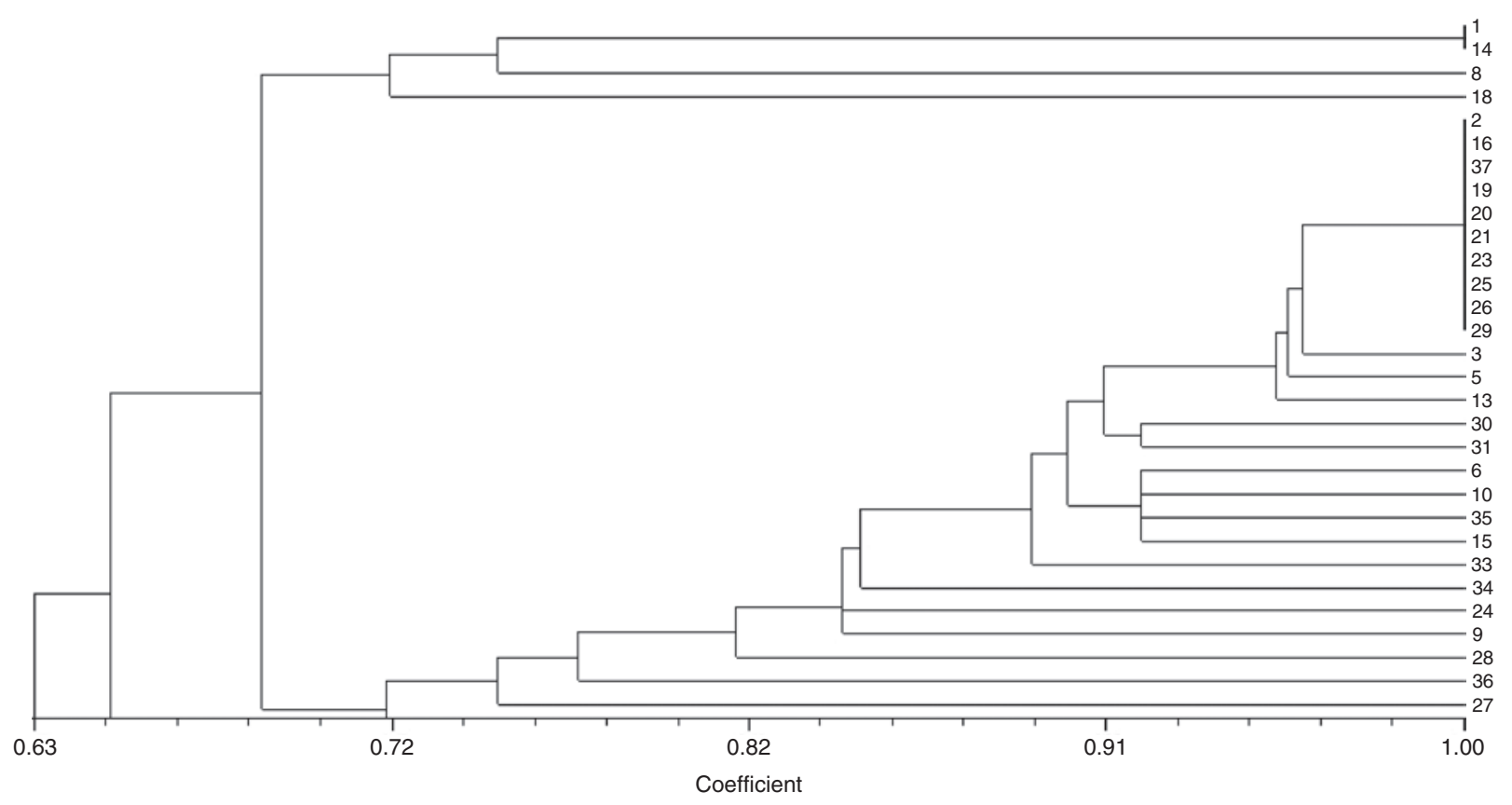

Figure 2: A phylogenetic tree analysis of PCR-RAPD.

slightly higher than that reported from the normal population of urban China [23], and lower than that reported from other parts of China [24-27]. Other studies which included urban Chinese population (migrant/maritime workers) reported comparable prevalence rates ranging from $41 \%$ to $44.9 \%$ [28-30]. A recent study which included dyspeptic patients from all parts of Mongolia reported an overall H. pylori infection rate of $80 \%$, which is much higher than that reported in our study [31]. Rapid urbanization in China has resulted in a likely decrease of $H$. pylori infections [9]. Although our study included both urban and rural populations, a majority of our patients were from the urban area

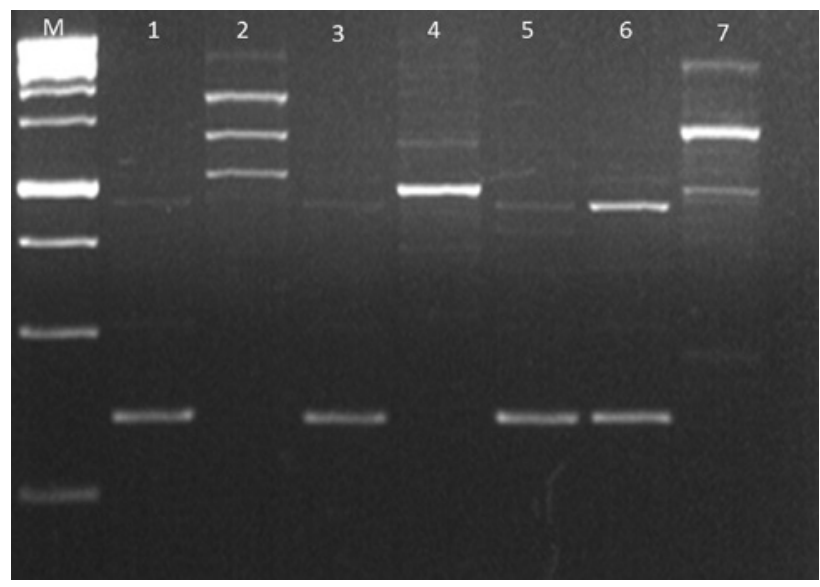

Figure 3: A representative gel picture showing the PCR-RFLP patterns, M: 100 bp DNA ladder, 1-7: Samples showing different DNA patterns.
(62.5\%) which might be the reason for a lower prevalence than that reported from other parts of China [23-27]. When compared to other countries, our results are consistent to those reported in healthy subjects from Japan (44.3\%) and in children and in adolescent subjects who underwent upper gastrointestinal endoscopy with gastric biopsies from Brazil (41.1\%) [32, 33]. The prevalence of $H$. pylori in our study is lower than that reported from some developing Asian countries; in patients who underwent upper gastrointestinal endoscopy from India (62\%), in dyspeptic patients from Bhutan (86\%) and Kazakhstan (76.5\%) [34-36]. The prevalence of $H$. pylori infection in dyspeptic patients from African countries including Ethiopia (65.7\%), Morocco (75.5\%) and Nigeria (93.6\%) were higher than that reported in our study [37-39]. The prevalence of $H$. pylori in our study is higher than that reported in normal subjects from western countries including the Netherlands (31.7\%) and Canada (37.9\%) while lower than those reported from Portugal (84.2\%), Turkey (82.5\%) and Mexico (52.2\%) [40-43]. Of the 39 (45.3\%) samples which were positive for $H$. pylori using the culture method, 29 samples from males were found to be positive compared to females $(n=10)$. In our study, males were predominantly infected by $H$. pylori which is consistent with that reported from China [23]. Smoking is considered as one of the independent risk factors for $H$. pylori infection which was higher in males compared to females in China [44]. Other postulated explanations include relative immunodeficiency and lower levels of plasma IgM in males [45]. 


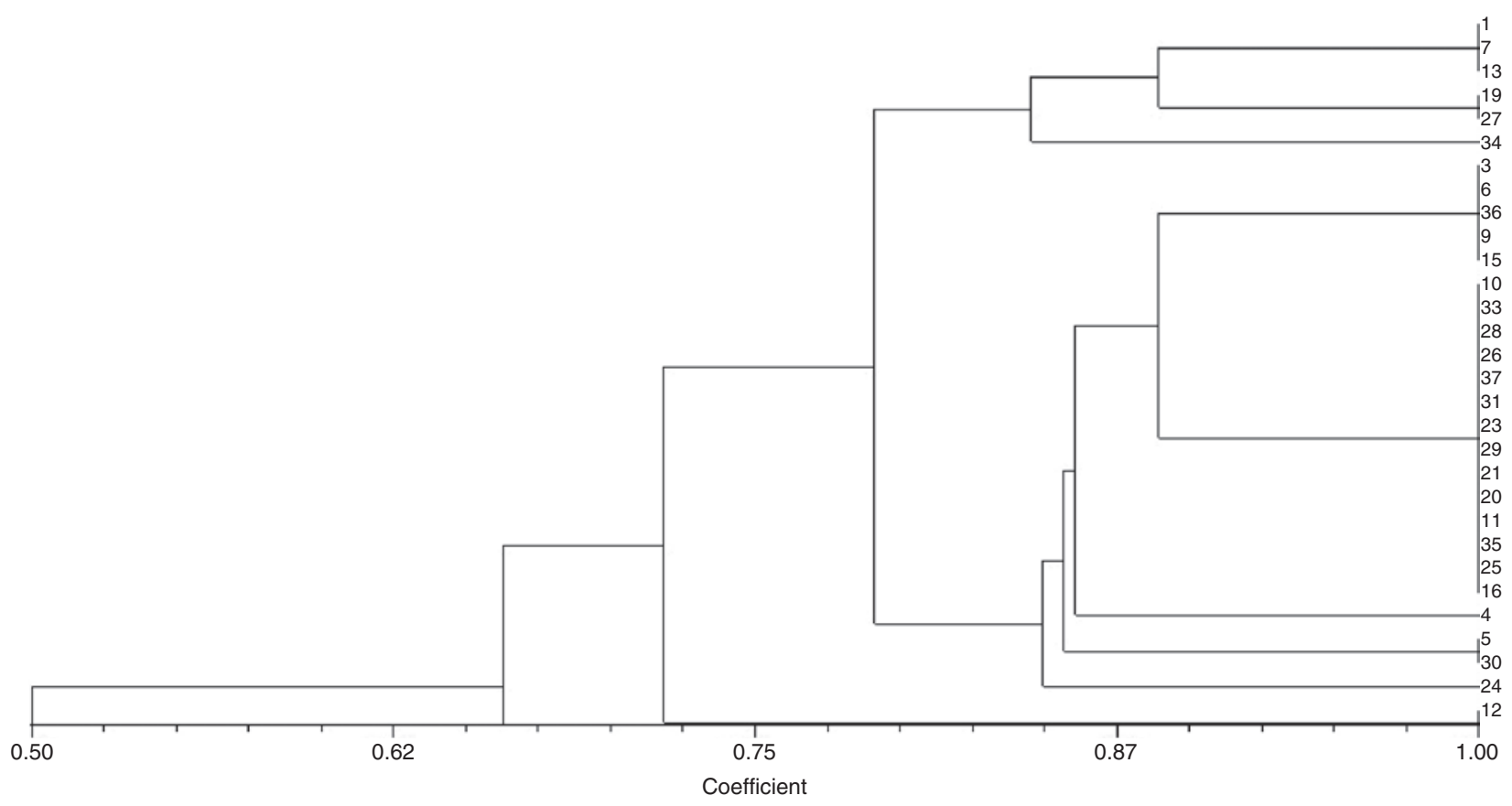

Figure 4: A phylogenetic tree analysis of PCR-RFLP.

The genomic heterogeneity is considered as a valuable tool in epidemiological studies [11]. The RAPD and RFLP techniques have been widely used in several epidemiological studies of $H$. pylori $[17,18,46]$. In our study, the RAPD analysis yielded a maximum of 17 different patterns whereas the RFLP yielded a maximum of six different patterns. The phylogenetic analysis of RAPD yielded 22 clusters while the RFLP yielded 10 clusters. In our study, both the RAPD and RFLP had good discriminatory power and yielded different patterns of strain variability. Our results were consistent with those reported by Lin et al. [11]. We found that most of the strains isolated from gastric ulcer patients showed almost similar patterns when tested using the RAPD and RFLP, respectively. We found that the RFLP pattern VI was associated with gastric ulcer, while the patterns III and VII were associated with gastritis. Apart from the isolates from gastric ulcer samples, other isolates showed diverse DNA fingerprints associated with diverse disease conditions. Thus, the majority of our stains showed high genetic variability yielding several different DNA fingerprints. This could indicate that $H$. pylori have epidemiological diversity and showed varied prevalence rates compared to other studies from different geographical locations [23-27, 32-43]. Although several reports indicate that the $H$. pylori infection is declining $[7,8,23]$, our results suggest that it is still higher compared to the developed countries [40-43]. In addition, the genetic variation among our isolates reiterates the requirement to investigate the clinical outcomes on a continues basis and a geographical-specific approach should be adopted for a better prophylaxis. We have included patients from the Chifeng and its affiliated hospitals and although this hospital recruits patients from four nearby provinces, the prevalence in this study may not truly reflect the entire population of China. Hence, further studies involving a large sample size and covering more regions of China are highly warranted.

\section{Conclusions}

The overall prevalence of $H$. pylori was $45.3 \%$. Despite reports on the declining trend in the prevalence of $H$. pylori infections, our prevalence rate was still higher than those reported from other developed countries. We suggest that one should not be complacent citing the reports on the declining trend on the prevalence; rather we should continuously monitor the trend in the prevalence of $\mathrm{H}$. pylori due to their high genetic variability.

Author contributions: All the authors have accepted responsibility for the entire content of this submitted manuscript and approved submission.

Research funding: None declared. Employment or leadership: None declared.

Honorarium: None declared. 
Competing interests: The funding organization(s) played no role in the study design; in the collection, analysis, and interpretation of data; in the writing of the report; or in the decision to submit the report for publication.

\section{References}

1. Bibi F, Alvi SA, Sawan SA, Yasir M, Sawan A, Jiman-Fatani AA, et al. Detection and genotyping of Helicobacter pylori among gastric ulcer and cancer patients from Saudi Arabia. Pak J Med Sci 2017;33:320-4.

2. Salama NR, Hartung ML, Muller A. Life in the human stomach: persistence strategies of the bacterial pathogen Helicobacter pylori. Nat Rev Microbiol 2013;11:385-99.

3. Franceschi F, Gasbarrini A, Polyzos SA, Kountouras J. Extragastric diseases and Helicobacter pylori. Helicobacter 2015;20(Suppl 1):40-6.

4. Hooi JK, Lai WY, Ng WK, Suen MM, Underwood FE, Tanyingoh D, et al. Global prevalence of Helicobacter pylori infection: systematic review and meta-analysis. Gastroenterology 2017;153:420-9.

5. Goh KL, Chan WK, Shiota S, Yamaoka Y. Epidemiology of Helicobacter pylori infection and public health implications. Helicobacter 2011;16(Suppl 1):1-9.

6. Roberts SE, Morrison-Rees S, Samuel DG, Thorne K, Akbari A, Williams JG. Review article: the prevalence of Helicobacter pylori and the incidence of gastric cancer across Europe. Aliment Pharmacol Ther 2016;43:334-45.

7. Habib AM, Alam MJ, Rudra B, Quader MA, Al-Forkan M. Analysis of Helicobacter pylori prevalence in Chittagong, Bangladesh, based on PCR and CLO test. Microbiol Insights 2016;9: 47-50.

8. Nimri LF, Matalka I, Bani Hani K, Ibrahim M. Helicobacter pylori genotypes identified in gastric biopsy specimens from Jordanian patients. BMC Gastroenterol 2006;6:27.

9. Nagy P, Johansson S, Molloy-Bland M. Systematic review of time trends in the prevalence of Helicobacter pylori infection in China and the USA. Gut Pathog 2016;8:8.

10. Moaddeb A, Fattahi MR, Firouzi R, Derakhshandeh A, Farshad S. Genotyping of the Helicobacter pylori cagA gene isolated from gastric biopsies in Shiraz, Southern Iran: a PCR-RFLP and sequence analysis approach. Jundishapur J Microbiol 2016;9:e30046.

11. Lin CW, Wang SF, Cheng KS. Genotyping of Helicobacter pylori isolates by random amplified polymorphic DNA and polymerase chain reaction-restriction fragment length polymorphism. M Taiwan J Med 1998;3:101.

12. Queiroz DM, Dani R, Silva LD, Santos A, Moreira LS, Rocha GA, et al. Factors associated with treatment failure of Helicobacter pylori infection in a developing country. J Clin Gastroenterol 2002;35:315-20.

13. Brenner H, Bode G, Boeing H. Helicobacter pylori infection among offspring of patients with stomach cancer. Gastroenterology 2000;118:31-5.

14. Figura N, Guglielmetti P, Rossolini A, Barberi A, Cusi G, Musmanno RA, et al. Cytotoxin production by Campylobacter pylori strains isolated from patients with peptic ulcers and from patients with chronic gastritis only. J Clin Microbiol 1989;27:225-6.

15. Huang J, Smyth CJ, Kennedy NP, Arbuthnott JP, Keeling PW. Haemagglutinating activity of Campylobacter pylori. FEMS Microbiol Lett 1988;56:109-12.

16. Skvarc M, Kofol R, Samo J, Kopitar AN, Tepes B, Ihan A. Multi locus sequence typing (MLST) used as a tool to confirm the ability of susceptible Helicobacter pylori strains to gain resistance to clarithromycin during eradication therapy. Hepatogastroenterology 2014;61:226-31.

17. Akopyanz N, Bukanov NO, Westblom TU, Berg DE. PCR-based RFLP analysis of DNA sequence diversity in the gastric pathogen Helicobacter pylori. Nucleic Acids Res 1992;20:6221-5.

18. Akopyanz N, Bukanov NO, Westblom TU, Kresovich S, Berg DE. DNA diversity among clinical isolates of Helicobacter pylori detected by PCR-based RAPD fingerprinting. Nucleic Acids Res 1992;20:5137-42.

19. Foxall PA, Hu LT, Mobley HL. Use of polymerase chain reactionamplified Helicobacter pylori urease structural genes for differentiation of isolates. J Clin Microbiol 1992;30:739-41.

20. Shahidi MA, Fattahi MR, Farshad S, Alborzi A. Validation of an in-house made rapid urease test kit against the commercial CLOtest in detecting Helicobacter pylori infection in the patients with gastric disorders. J Res Med Sci 2012;17:212-6.

21. Farshad S, Japoni A, Shahidi MA, Hosseini M, Alborzi A. An improvement in isolation and preservation of clinical strains of Helicobacter pylori. Trop Gastroenterol 2011;32:36-40.

22. Ozbey G, Dogan Y, Demiroren K, Ozercan IH. Prevalence of Helicobacter pylori in children in eastern Turkey and molecular typing of isolates. Braz J Microbiol 2015;46:505-11.

23. Yu X, Yang X, Yang T, Dong Q, Wang L, Feng L. Decreasing prevalence of Helicobacter pylori according to birth cohorts in urban China. Turk J Gastroenterol 2017;28:94-7.

24. Chen J, Bu XL, Wang QY, Hu PJ, Chen MH. Decreasing seroprevalence of Helicobacter pylori infection during 1993-2003 in Guangzhou, southern China. Helicobacter 2007;12:164-9.

25. Chen SY, Liu TS, Fan XM, Dong L, Fang GT, Tu CT, et al. [Epidemiological study of Helicobacter pylori infection and its risk factors in Shanghai]. Zhonghua Yi Xue Za Zhi 2005;85:802-6.

26. Cheng H, Hu F, Zhang L, Yang G, Ma J, Hu J, et al. Prevalence of Helicobacter pylori infection and identification of risk factors in rural and urban Beijing, China. Helicobacter 2009;14:128-33.

27. Wong BC, Lam SK, Ching CK, Hu WH, Kwok E, Ho J, et al. Differential Helicobacter pylori infection rates in two contrasting gastric cancer risk regions of South China. China Gastric Cancer Study Group. J Gastroenterol Hepatol 1999;14:120-5.

28. Cao H, Qu R, Zhang Z, Kong X, Wang S, Jiang K, et al. Sporadic fundic gland polyps are not associated with proton pump inhibitors therapy but negatively correlate with Helicobacter pylori infection in China. Chin Med J 2014;127:1239-43.

29. Hu D, Shao J, Wang L, Zheng H, Xu Y, Song G, et al. Prevalence and risk factors of Helicobacter pylori infection in Chinese maritime workers. Annal Hum Biol 2013;40:472-6.

30. Xia P, Ma MF, Wang W. Status of Helicobacter pylori infection among migrant workers in Shijiazhuang, China. Asian Pac J Cancer Prev 2012;13:1167-70.

31. Khasag O, Boldbaatar G, Tegshee T, Duger D, Dashdorj A, Uchida T, et al. The prevalence of Helicobacter pylori infection and other risk factors among Mongolian dyspeptic patients who have a 
high incidence and mortality rate of gastric cancer. Gut Pathog 2018;10:14.

32. Pacheco SL, Ogata SK, Machado RS, Patricio FR, Pardo ML, Kawakami E. Diagnosis of Helicobacter pylori infection by means of reduced-dose (1)(3)C-urea breath test and early sampling of exhaled breath. J Pediatr Gastroenterol Nutr 2013;57:607-11.

33. Ueda J, Gosho M, Inui Y, Matsuda T, Sakakibara M, Mabe K, et al. Prevalence of Helicobacter pylori infection by birth year and geographic area in Japan. Helicobacter 2014;19:105-10.

34. Adlekha S, Chadha T, Krishnan P, Sumangala B. Prevalence of Helicobacter pylori infection among patients undergoing upper gastrointestinal endoscopy in a medical college hospital in kerala, India. Ann Med Health Sci Res 2013;3:559-63.

35. Benberin V, Bektayeva R, Karabayeva R, Lebedev A, Akemeyeva K, Paloheimo L, et al. Prevalence of $\mathrm{H}$. pylori infection and atrophic gastritis among symptomatic and dyspeptic adults in Kazakhstan. A hospital-based screening study using a panel of serum biomarkers. Anticancer Res 2013;33:4595-602.

36. Dorji D, Dendup T, Malaty HM, Wangchuk K, Yangzom D, Richter JM. Epidemiology of Helicobacter pylori in Bhutan: the role of environment and Geographic location. Helicobacter 2014;19:69-73.

37. Benajah DA, Lahbabi M, Alaoui S, El Rhazi K, El Abkari M, Nejjari $C$, et al. Prevalence of Helicobacter pylori and its recurrence after successful eradication in a developing nation (Morocco). Clin Res Hepatol Gastroenterol 2013;37:519-26.

38. Mathewos B, Moges B, Dagnew M. Seroprevalence and trend of Helicobacter pylori infection in Gondar University Hospital among dyspeptic patients, Gondar, North West Ethiopia. BMC Res Notes 2013;6:346.

39. Olokoba AB, Gashau W, Bwala S, Adamu A, Salawu FK. Helicobacter pylori infection in Nigerians with dyspepsia. Ghana Med J 2013;47:79-81.

40. Bastos J, Peleteiro B, Barros R, Alves L, Severo M, de Fatima Pina $M$, et al. Sociodemographic determinants of prevalence and incidence of Helicobacter pylori infection in Portuguese adults. Helicobacter 2013;18:413-22.

41. Ozaydin N, Turkyilmaz SA, Cali S. Prevalence and risk factors of Helicobacter pylori in Turkey: a nationally-representative, cross-sectional, screening with the (1)(3)C-Urea breath test. BMC Public Health 2013;13:1215.

42. Sethi A, Chaudhuri M, Kelly L, Hopman W. Prevalence of Helicobacter pylori in a First Nations population in northwestern Ontario. Can Fam Physician 2013;59:e182-7.

43. van Blankenstein $M$, van Vuuren AJ, Looman CW, Ouwendijk $M$, Kuipers EJ. The prevalence of Helicobacter pylori infection in the Netherlands. Scandinavian J Gastroenterol 2013;48:794-800.

44. Zhu Y, Zhou X, Wu J, Su J, Zhang G. Risk factors and prevalence of Helicobacter pylori Infection in persistent high incidence area of gastric carcinoma in Yangzhong city. Gastroenterol Res Pract 2014;2014:481365.

45. Morell V. Zeroing in on how hormones affect the immune system. Science 1995;269:773-5.

46. Fujimoto S, Marshall B, Blaser MJ. PCR-based restriction fragment length polymorphism typing of Helicobacter pylori. J Clin Microbiol 1994;32:331-4. 